\title{
IMPROVING THERMAL PERFORMANCE OF CHILLED WATER STORAGE TANK- A NUMERICAL STUDY
}

\section{SWATI PATHADE \& R. S. MAURYA}

Department of Mechanical Engineering, Sardar Patel College of Engineering, Maharashtra, India

ABSTRACT
This study investigated the effect of geometrical parameters on the ability of a storage to maintain the stratification by
preventing distortion of thermocline during charging and discharging cycles.
Existing methods and empirical relations have been applied to design a chilled water storage tank for a hypothetical
case of emergency cooling requirement of a data science center for 12 minutes. The effect of diffuser diameter, inlet
height and Reynolds number have been studied. The idea of using perforated dampers to damp the turbulence occurring
at high Reynolds number is introduced and empirical relations for the dampers are suggested. The validation of storage
tank design with perforated dampers is carried out at various mass flow rates in the range of Reynolds number 792 to
6072 for storage tank of different diameters.
KEYWORDS: Thermal Energy Storage, Stratification, Diffusers, Charge-Discharge Cycle, Thermocline \& Perforated
Plates

Received: Jun 08, 2020; Accepted: Jun 28, 2020; Published: Sep 05, 2020; Paper Id.: IJMPERDJUN20201080

\section{INTRODUCTION}

Due to increased average global temperature during daytime building cooling load consumes major part of total energy consumption. Peak of demands occurs in the daytime which can be met either by constructing bigger plant or borrowing from neighboring utilities to compensate shortage. These solutions require high capital cost and long duration for carrying out construction. Using chilled water storage is a low cost and effective solution to meet the peak energy demand for short duration intensive applications. This system simply transfers peak electric loads from on-peak period to off-peak period. It works on the principle of thermal stratification and thermocline. In a naturally stratified storage tank, chilled and warm water are stored together in one tank without using any physical separator. Stratification consists of three zones viz. chilled water zone resides in the tank bottom due to higher density, warm water zone resides in the tank top due to lower density and the interfacial zone stays between them to prevent the mixing between the chilled and warm water. This zone is called the thermocline or temperature gradient. The key attribute of effective sensible storage is effective thermal separation, i.e., prevention of thermal mixing of warm and cool storage medium. Thus, as long as the separation or thermocline is maintained, we can say that the thermal storage tank is working satisfactorily. Figure1 shows the flow path diagram of fluid to/from the storage tank. During charging (off peak period), tank receives chilled water at the bottom port through the chillers and thermocline moves up by supplying warm water to the chillers. During discharging (in case power failure or other requirements) chilled water moves to load centers from bottom port and water (warm) from loads comes back to the storage tank causing thermocline to move down. During charging and discharging both, the thermocline should not get disturbed due the turbulence caused by entry and exit of the water. To maintain a good thermal stratification, the diffusers are used which helps to reduce turbulent mixing. 


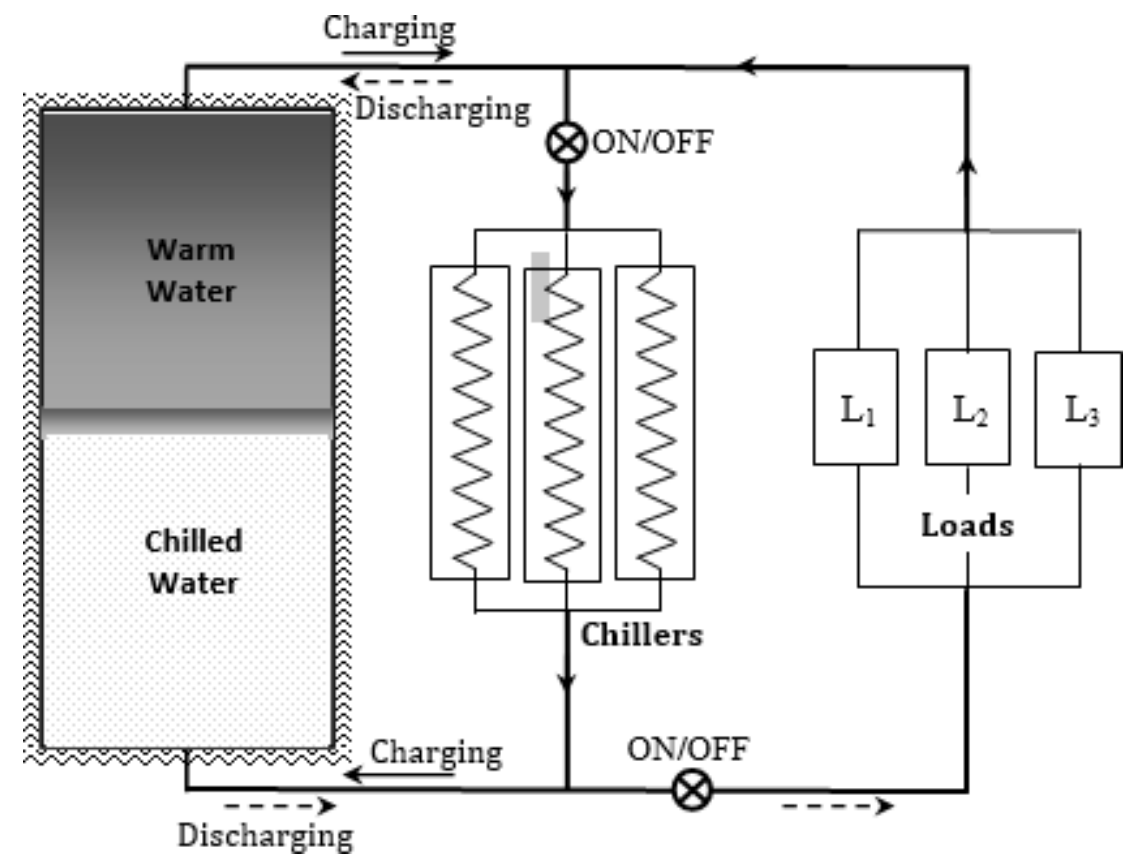

Figure 1: Charge and Discharge Cycle.

Chilled water storage system has been extensively investigated by several researchers to make more efficient. The geometry of storage system is an important parameter. A simulation of the temperature gradient existing across thermocline at different $\mathrm{L} / \mathrm{D}$ for discharging cycle was investigated by Tipasriet al. (2019) [1]. The L/D ratios of the tank were varied as $0.7,0.8,1.1,1.2,1.4,1.6$ and 2.0 with a constant of volume of $1,755 \mathrm{~m}^{3}$. They concluded that the H/D $=2.0$ gave highest remaining cold water. Nelson et al. (1999) [2] investigated a cylindrical storage system to estimate the effect of the aspect ratio (L/D) on its performance. They concluded that aspect ratio beyond 3 doesn't have any significant effect on the thermal performance of storage system.Hassan (2018) [3] studied various types of inlet diffusers, an elbow, tworing linear and radial circular diffusers. The results obtained suggested that the two-ring linear circular diffuser produced better stratification than other two diffusers for various flow rates. Karim. (2011) [4] has experimentally investigated that the formation of thermocline can be ensured by designing the diffuser with Froude number equal to 1 and equal pressure drop. Lower Froude number causes unequal pressure drop and unequal flow from different openings. Froude number is defined as the ratio of the inertia force to the buoyancy force acting on fluid. Musser et al. (2001) [5] defined that for radial diffuser, $h_{i}$ is the width between the plate of radial diffuser and spreading surface. For lower diffuser, spreading surface is tank floor and for upper diffuser, it is water free surface. Froude number is used to calculate inlet diffuser height whereas Reynolds number is used to determine whether the flow is laminar or turbulent.

$$
\operatorname{Re}=\frac{\mathrm{q}}{\mathrm{v}}
$$

Where $\mathrm{q}$ is the flow rate for unit diffuser length, and $v$ is kinematic viscosity of working water. As per Dorgan and Elleson (1993) [6], unlike Froude number criteria the Reynolds number criteria is controversial.Bahnfleth and Musser (1998) [7] have investigated that for very short tanks, recommended design values of Reiis near about 200 and for large tanks having depth greater than $40 \mathrm{ft} .(12.2 \mathrm{~m})$ is about 2000. However, some report suggests that all tanks with Reynolds number on the order of 10,000 stratify well and experience good performance of diffuser. 


\section{PROBLEMDESCRIPTION}

The problem is associated to a chilled water storage tank which is designed to meet the emergency cooling load of 40TR of a data science center. The storage tank is expected to meet the cooling load requirement for about 12 minutes as per the standard chiller restart time after power outage M.Lin. et.al. (2015) [8]. The tank is cylindrical with diameter of $1 \mathrm{~m}$ and completely insulated to prevent any heat loss. It receives chilled water and hot water at $4^{\circ} \mathrm{C}$ and $17^{\circ} \mathrm{C}$ respectively through a 2-inch duct. Radial diffuser is used for entry and exit of hot and cold fluid. The diffuser is designed at inlet Froude Number $(F r)$ equal to 1 and Reynolds number $\left(R e_{i}\right)$ equal to 1056 in order to prevent destruction of thermocline during charging and discharging. ASHRAE guidelines recommend that the Reynolds number of such system should be around 200. So, during the operation of such chilled water thermal storage tank, there is a probability of destruction of thermocline due to high Reynolds number. Therefore, system needs certain internal geometrical modification at the exit of diffuser so that the thermocline is saved from its destruction. It is a challenging task which needs deeper investigation to develop a sound design of high capacity chilled water storage system. Figure 2 shows schematic diagram of a storage tank with a thermocline.

The objective of present work is to design a storage tank for 40TR emergency cooling load which can meet the requirement for 12 minutes and study the effect of diffuser diameter, inlet height from tank floor and Reynolds number on behavior of thermocline. And recommend modification in its internal configuration with required investigation.

To complete the investigation the work is proposed to be executed in three parts:

\section{A: Sizing of the Storage Tank and Diffuser}

This is theoretical calculation-based objective which includes the calculation for mass flow rate for given load, deciding size of the storage tank, estimating diffuser diameter, diffuser inlet height using standards.

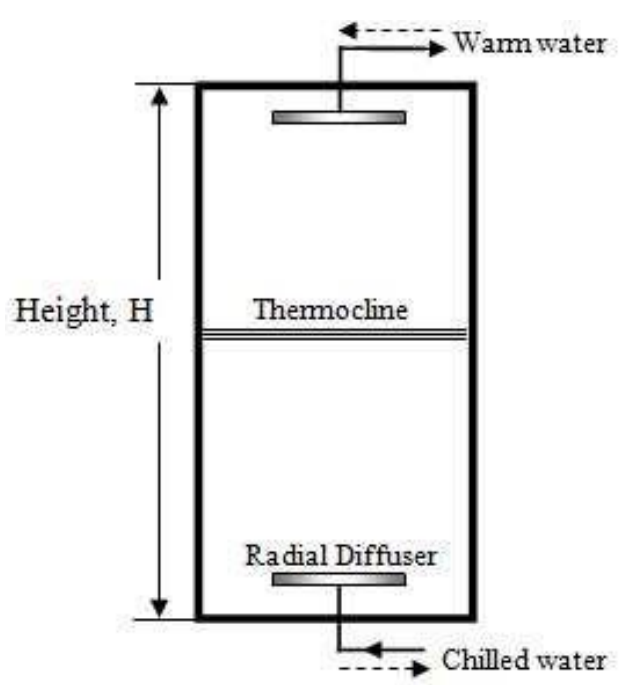

a. Insulated Storage Tank

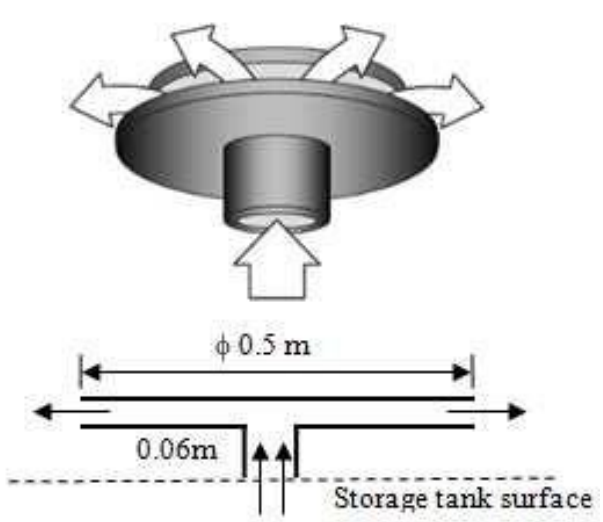

b. Radial Diffuser

Figure 2: Schematic Diagram of (a)Insulated Storage Tank, and (b) Radial Diffuser.

\section{B: Numerical Investigation of Transient Behavior of The Thermal Stratification}

The work includes to study the transient effect of different geometrical and operating parameters of the storage tank on the 
thermocline.

\section{C: Investigating the Effect of Flow Damper Located Near Radial Diffuser on The Performance of Thermocline and Flow Structure Evolving Inside the Tank.}

The performance of thermocline with damper is investigated in this section.

The numerical method has been used for investigation by using a commercial software 'ANSYS Fluent'.

\section{THEORETICAL ANALYSIS}

\section{A. Sizing of the Storage Tank and Diffuser}

In order to meet the cooling load requirement of $40 \mathrm{TR}$ for 12 minutes a mass flow rate $(\dot{m})$ of $2.6 \mathrm{~kg}$ per second is required. It is calculated by energy balance,

Cooling load $=40 \mathrm{TR}$

$40 T R \times 3.5=\dot{m} \times C p \times(T h-T c)$

where, $T h=17^{\circ} \mathrm{C}$ and $T c=4^{\circ} \mathrm{C}$.

The tank should store $1842 \mathrm{~kg}$ water with a volume requirement of about $1.9 \mathrm{~m}^{3}$.

The most convenient shape i.e. a cylindrical storage tank is selected whose final dimension is fixed by considering $20 \%$ extra volume for internal fittings and safe operations for designed conditions. The size of cylindrical storage tank determined as diameter to be of $1 \mathrm{~m}$ and height $3 \mathrm{~m}$. It provides a useful storage of volume of chilled water of $2.36 \mathrm{~m}^{3}$. The pipe for charging and discharging of the tank fixed to be of 2-inch diameter and flow rate is fixed by mass balance equation.

The performance of the stratified storage tank depends on a number of parameters, such as- discharge mass flow rate of chilled water (decided by loads), fluid entry / exit velocity of diffuser, tank size, diffuser radius, distance of diffuser from tank surface etc.

\section{B. Diffuser Design}

The diffuser design is important to maintain effective thermocline for satisfactory performance. Theradial diffuser, as shown in figure 2, consists of two circular plate with a narrow gap in between with inlet and outlet pipe at the center. Fluid enters or exists through the peripheral openings. The velocity at the diffuser is calculated by using continuity equation and the height of the diffuser from tanks horizontal surface is calculated by considering Froude number unity (Froude number should never be more than 2). Table 1 shows the estimated value of different parameters as per design guidelines and empirical relations.

Table 1: Tank and Diffuser Parameters

\begin{tabular}{|c|c|l|c|}
\hline Parameters & Value & \multicolumn{1}{|c|}{ Parameters } & Value \\
\hline Cold water temperature & $4^{\circ} \mathrm{C}$ & Height of tank, $\mathrm{H}$ & $3 \mathrm{~m}$ \\
\hline Hot water temperature & $17^{\circ} \mathrm{C}$ & Pipe size, $($ dia. $)$ & $0.05 \mathrm{~m}$ \\
\hline Mass flow rate & $2.6 \mathrm{~kg} / \mathrm{s}$ & Radial diffuser diameter $(\mathrm{d})$ & $0.5 \mathrm{~m}$ \\
\hline Required volume & $1.872 \mathrm{~m}^{3}$ & Diffuser inlet height $(\mathrm{h})$ & $0.06 \mathrm{~m}$ \\
\hline Diameter of tank, D & $1 \mathrm{~m}$ & Diffuser disk spacing $(\mathrm{s})$ & $0.04 \mathrm{~m}$ \\
\hline
\end{tabular}

\section{NUMERICAL INVESTIGATION}


The thermal stratification in a storage tank is achieved due to density difference of hot and cold fluid and absence of fluid momentum inside the tank. Although the thermocline separates hot and cold zone, but during charging and discharging operation it may be severely damage due to entering or leaving fluid momentum. Froude number less than 2 and Reynolds number less than 200 ensures satisfactory performance of the system. The diffuser should be designed such that the flow enters or leave the tank at low velocity (with least turbulence). The development of flow parameters inside the tank can be captured mathematically by using energy, mass and momentum balance considering steady/ transient, incompressible flow with negligible body force.

\section{A. Mathematical Model}

\section{Mass Balance Equation}

$\frac{\partial u}{\partial x}+\frac{\partial v}{\partial y}=0$

\section{Momentum Balance Equation}

X-Momentum Equation

$\rho\left(\frac{\partial \mathrm{u}}{\partial \mathrm{t}}+u \frac{\partial u}{\partial x}+\mathrm{v} \frac{\partial \mathrm{u}}{\partial \mathrm{y}}\right)=\rho g_{x}-\frac{\partial \mathrm{p}}{\partial \mathrm{x}}+\mu\left(\frac{\partial^{2} u}{\partial \mathrm{x}^{2}}+\frac{\partial^{2} u}{\partial \mathrm{y}^{2}}\right)$.

Y-Momentum Equation

$\rho\left(\frac{\partial \mathrm{v}}{\partial \mathrm{t}}+u \frac{\partial \mathrm{v}}{\partial \mathrm{x}}+\mathrm{v} \frac{\partial \mathrm{v}}{\partial \mathrm{y}}\right)=\rho g_{\mathrm{y}}-\frac{\partial \mathrm{p}}{\partial \mathrm{y}}+\mu\left(\frac{\partial^{2} v}{\partial \mathrm{x}^{2}}+\frac{\partial^{2} v}{\partial \mathrm{y}^{2}}\right)$

\section{Energy Balance Equation}

$\rho C p\left[\frac{\partial \mathrm{T}}{\partial \mathrm{t}}+\left(V^{\rightarrow} \cdot \nabla\right) T\right]=k \nabla^{2} \mathrm{~T}+\phi$

\section{B. Boundary Conditions}

There are three domain which needs boundary condition - diffuser inlet, outlet, wall. The temperature of two different fluid zone - chilled and warm water.

The boundary conditions applicable to present investigation are as follows:

Inlet: Constant velocity

Outlet: Constant velocity (for same mass flow rate as that of inlet)

Wall: No-slip condition

Warm water temperature: $290 \mathrm{~K}$

Chilled water temperature:277K

\section{NUMERICAL IMPLIMENTATION}

A computational domain is selected for the investigation. It is a two-dimensional rectangular figure representing a vertical section passing through the storage tank along its axis. It is filled with the chilled water at the bottom half of the tank and 
warm water in top half of the tank separated by a thermocline. Two diffuser- one in hot zone and other in chilled zone is a part of the computational domain. They are of diameter $0.5 \mathrm{~m}$ and placed $0.06 \mathrm{~m}$ away from the tank bottom surface. Flow enter and exits in radial direction through the diffuser. The domain considered is shown in fig.3(a). To understand the effect of various geometrical parameters, different cases are studied.

In order to capture the propagation of interface and to ensure that the temperature gradient differentiated, a sufficiently fine mesh system has been used without any boundary layer meshing. Whole computational domain is meshed with quad elements of size $10^{-2} \mathrm{~m}$ at the face to avoid mesh quality related issues. The meshed domain is shown in figure $3(b)$.

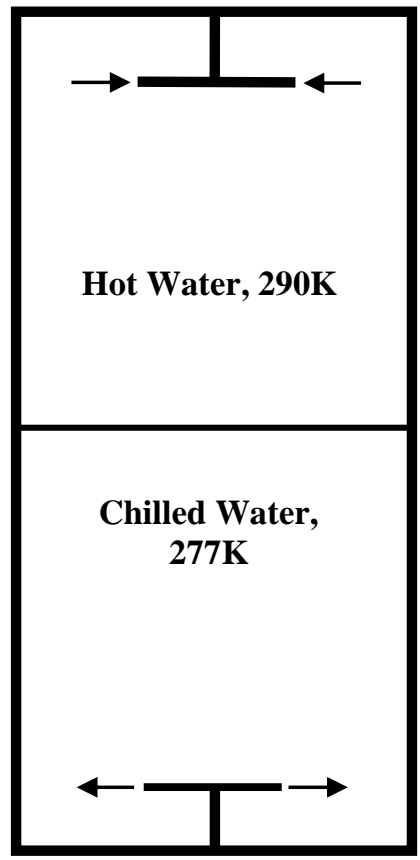

(a)

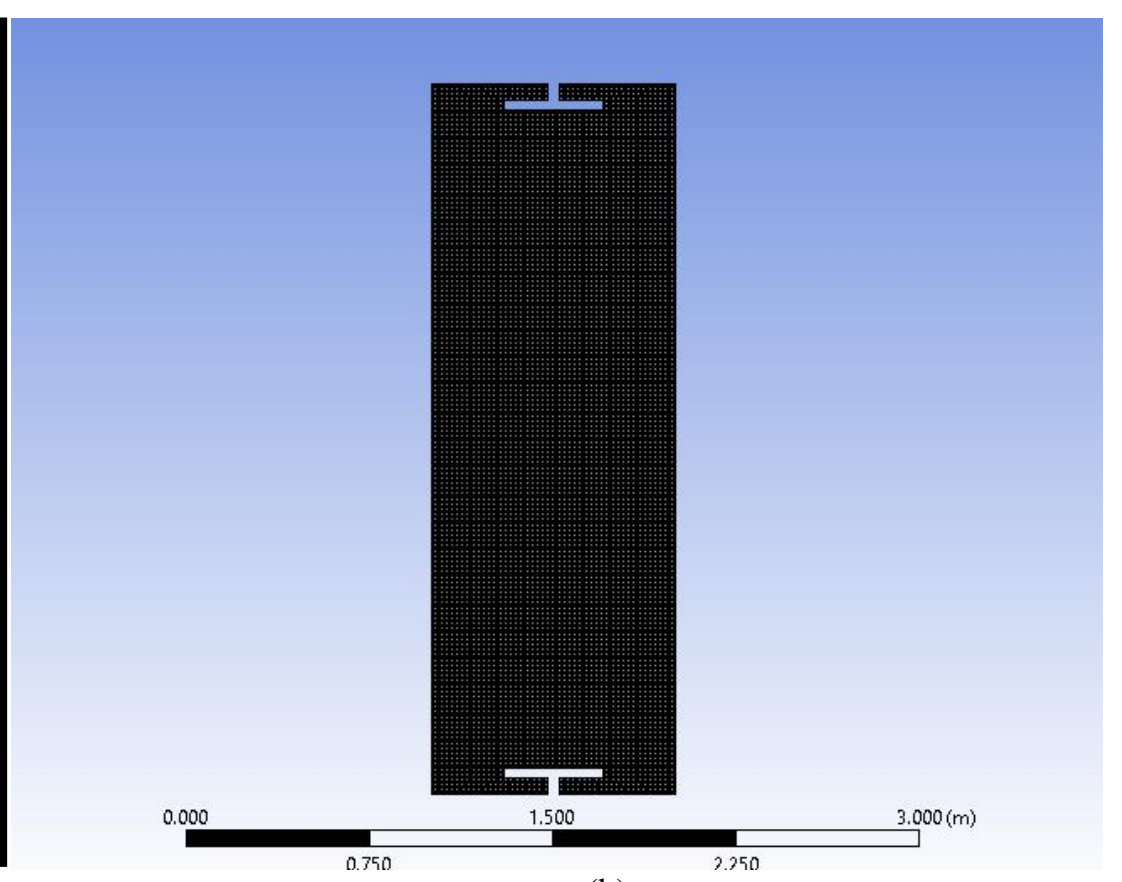

(b)

Figure 3: (a) Computational Domain and (b) Meshed Domain.

Numerical Models: Energy, Viscous-Laminar

Material properties: The density and dynamic viscosity of water at chilled and warn state is mentioned below.

\begin{tabular}{|l|c|c|}
\hline Temperature (K) & $\mathbf{2 7 7}$ & $\mathbf{2 9 0}$ \\
\hline$\rho\left(\mathrm{kg} / \mathrm{m}^{3}\right)$ & 1000 & 998.2 \\
\hline$\mu(\mathrm{kg} / \mathrm{ms})$ & $1567 \times 10^{-06}$ & $1083 \times 10^{-06}$ \\
\hline
\end{tabular}

Solution Method: Some of the important numerical settings are tabulated below,

\begin{tabular}{|l|l|}
\hline \multicolumn{1}{|c|}{ Parameters } & \multicolumn{1}{c|}{ Set up } \\
\hline Pressure velocity coupling & SIMPLE algorithm \\
\hline Spatial discretization for gradient & Least square cell based \\
\hline Spatial discretization for pressure & Second order upwind \\
\hline Spatial discretization for momentum and energy & Second order upwind \\
\hline
\end{tabular}

Time step=1sec, Max iterations/Time step=20

The convergence criterion is set to be $10^{-3}$. Investigated results are analyzed in CFD post. 


\section{RESULTS ANDDISCUSSIONS}

The outcome of the work is presented under following two categories:

\section{- Numerical Investigation of Transient Behavior of The Thermal Stratification}

This is a two-dimensional numerical flow analysis of existing designs of the chilled water storage tank and an assessment of few important parameter on the system performance.

\section{- Modification in The Diffuser Setting for Better System Performance}

This section presents the investigated report where flow dampers of different configurations has been used and an optimum one is recommended.

\subsection{Numerical Investigation of Transient Behavior of The Thermal Stratification}

During charging and discharging operation, the thermal stratification inside the storage tank may get disturbed (destructed) by several parameters. A simulation of flow through diffuser inside storage tank with thermocline located at the mid horizontal plane, is carried out (based on theoretical sizing of the storage tank and the diffuser) to observe the flow pattern developing inside the tank and causing damage to the stratification. Figure 4 shows velocity contour and temperature distribution at time $105 \mathrm{~s}$ after the charging started. It can be seen from the temperature contour that thermocline is rising up during charging. The flow emerging out from the bottom radial diffuser rises up along the wall. This is due momentum in the emerging liquid and the pressure gradient (due to hydrostatic effect) present in the system. Rising plume of chilled water disturbs the thermocline (mixing of chilled and warm fluid starts) after certain time depending on thermocline location during charging operation.

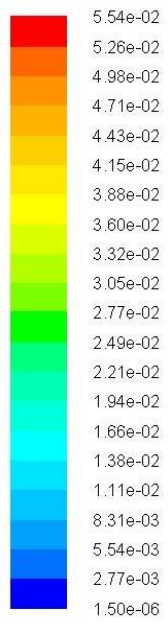

(a) Velocity Contour
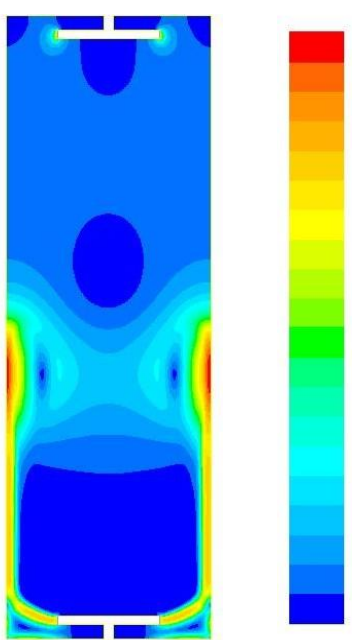

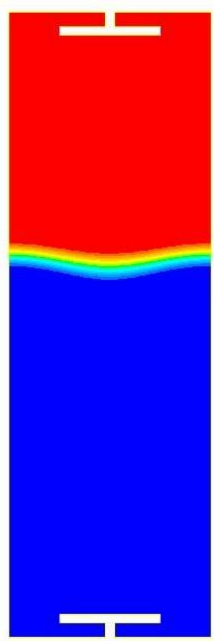

\section{Figure 4: Temperature and Velocity Contour at Time 105s.}

As theoretical calculation for sizing of tank and diffuser doesn't ensure a good performance, so a deeper investigation of the problem of thermocline disturbance is required. To support the completeness in the study few parametric studies has been performed considering key diffuser's parameters. 
- $\quad$ The diffuser diameter (d);

- $\quad$ The inlet height $(\mathrm{h})$;

- The inlet Reynolds number $\left(\operatorname{Re}_{i}\right)$.

\section{Validation of The Model}

No experimental data is available to validate the present work where thermocline exist and moves with charging and discharging. Hasan et al. [3] did an experimental work on a cylindrical storage tank being charged in presence of thermocline. An elbow diffuser was used for charging and the temperature gradient across thermocline was measured. Following parameters were considered for the study.

Tank diameter :0.4m

Tank Height $: 1.1 \mathrm{~m}$

Cold water temperature: $4.1^{\circ} \mathrm{C}$

Hot water temperature: $30^{\circ} \mathrm{C}$

Charging flow rate: $1.35 \mathrm{LPM}$

Same case is simulated with present numerical scheme for its validation. Figure 5(a) shows temperature contour located at the height of $30 \mathrm{~cm}$ from bottom of the tank. Figure 5(b) shows the thermocline thickness in terms non-dimensional temperature $(\Theta)$ and height of the tank $(\mathrm{Z})$ for experiment and present work both. A closeness in the result can be observed.

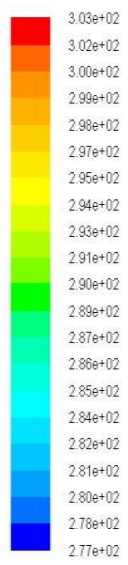

(a)

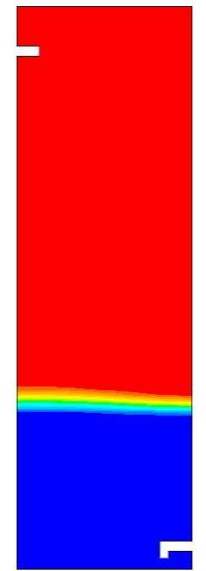

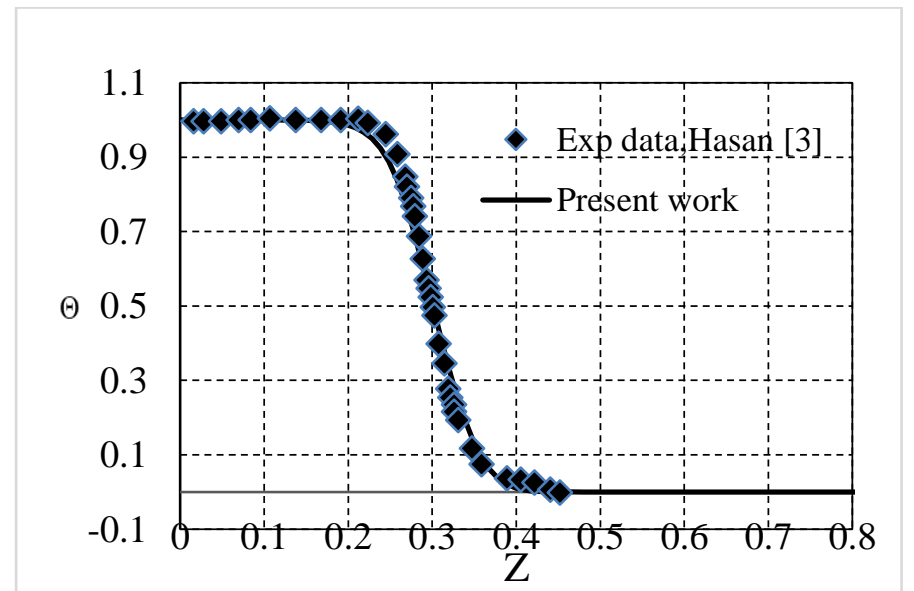

(b)

Figure 5: Validation (a) Temperature Contour, (b) Temperature Distribution Across Thermocline.

\section{a) Effect of Diffuser Diameter on Thermocline}

Keeping storage tank of the same size, the diffuser diameter is varied to $0.3 \mathrm{~m}, 0.4 \mathrm{~m}, 0.6 \mathrm{~m}$ and $0.7 \mathrm{~m}$ to assess the effect of their size on the thermocline stability. This is done by assuming that thermocline initially exist at mid-height of the tank and the charging operation starts. Chilled water enters and thermocline moves up. Higher momentum fluid (depending on charging rate) is expected to take lesser time to disturb the thermocline. Figure 6(a) shows the shape of thermocline interface after $100 \mathrm{~s}$ of charging under different diameter of the diffuser. The maximum time for which thermocline remains 
stable is shown in fig. 6(b). As diameter of diffuser increases thermocline tends to be more stable at a given charging rate. This behavior may be attributed to the reduction in fluid momentum due nearness of storage tank wall to the diffuser exit. So, it can be concluded that the diffuser diameter should be around 0.5 times of tank diameter for satisfactory operation.

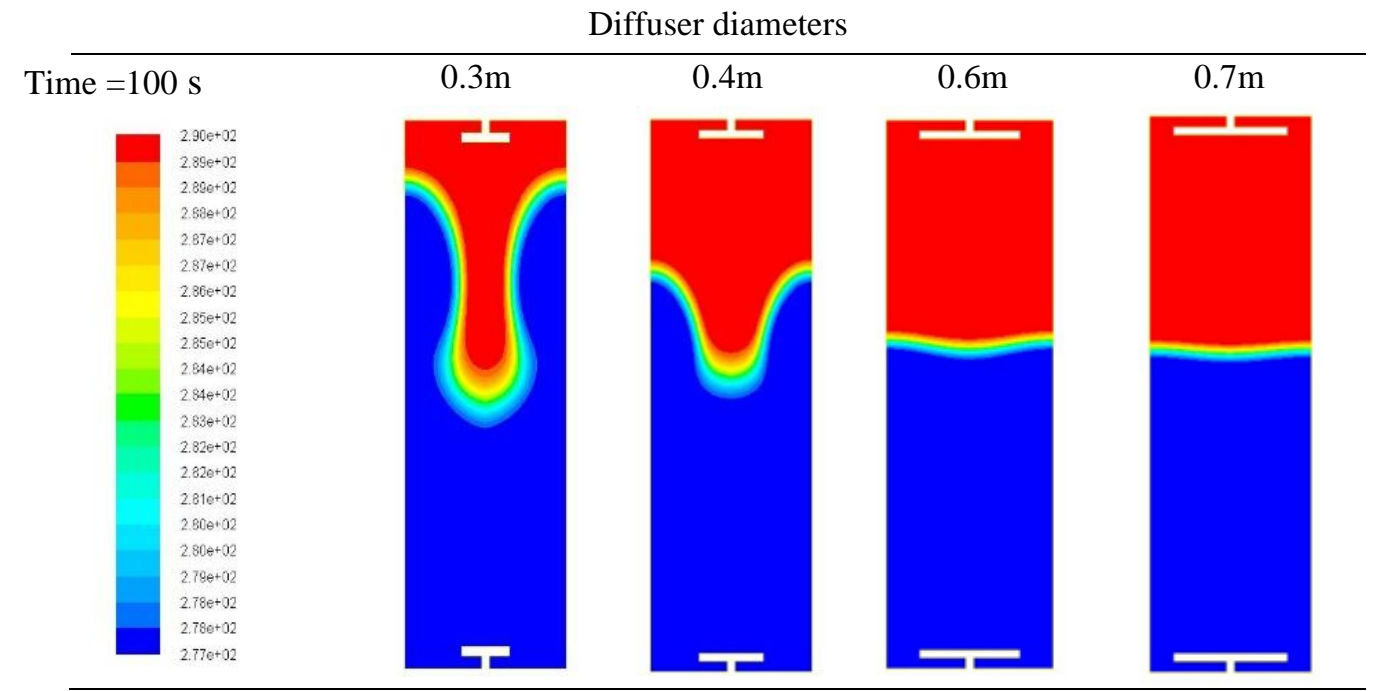

(a)

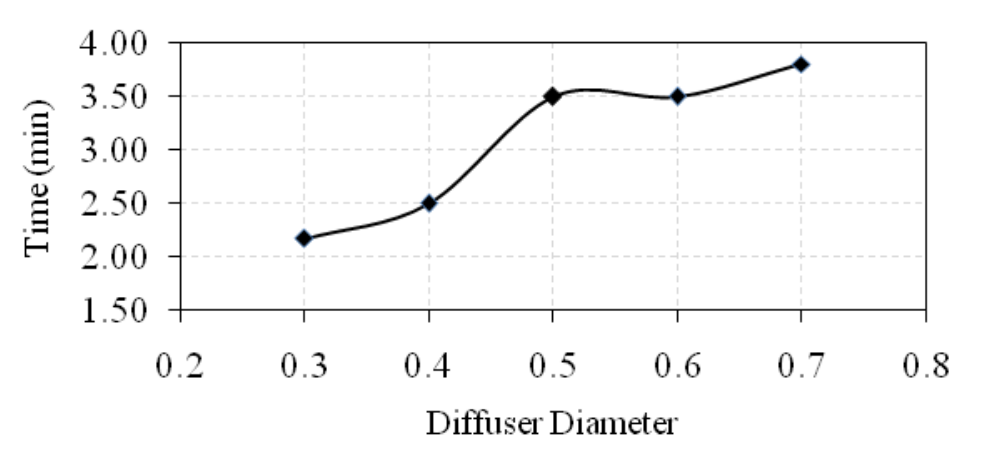

(b)

Figure 6: (a) Thermocline Interface Structure, (b) Effect of diff. dia. on Thermocline Stability.

\section{b) Effect of Diffuser Height ' $\mathrm{H}_{\mathrm{i}}$ ' From Tank Horizontal Surface}

The Froude number is an important indication to satisfactory performance of a stratified thermal storage tank. It should be less than 2 as per recommendation in several literatures. It shows the competitive effect of the buoyancy and inertia force. Higher value of this number causes jet formation at the downstream of inlet and results to mixing. Diffuser height ' $h{ }^{\prime}$ ' effects Froude number. Figure 7 shows the effect of variation of ' $\mathrm{h}_{\mathrm{i}}$ ' on the Froude number and corresponding time taken by charging fluid to catching up the upward moving thermocline (disturbing the stability of the thermocline). Lower the Froude number, better is the thermocline stability. So, diffuser height from tank's horizontal surface should not be very small. 


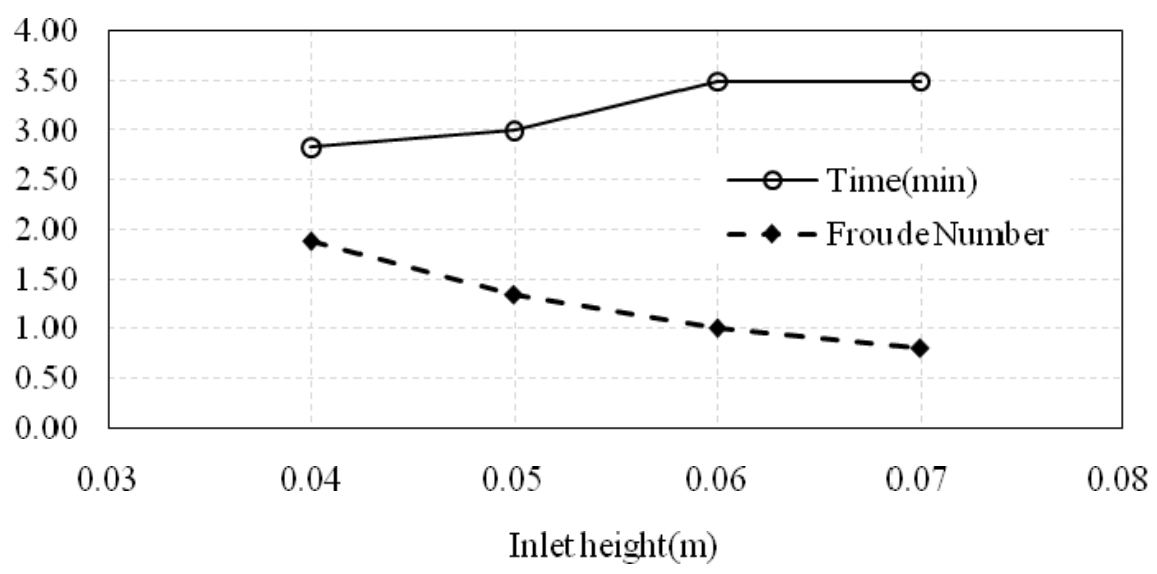

Figure7: Effect of Inlet Height on Thermocline Stability.

\section{c) Effect of Inlet Reynolds Number on the Thermocline Stability}

Inlet Reynolds number indicates the inertial effect of the fluid entering inside the storage tank during charging operation. High $\mathrm{Re}_{i}$ chilled water has high potential to damage the thermal stratification, if inertial forces are not dampened out by any other mechanical means.

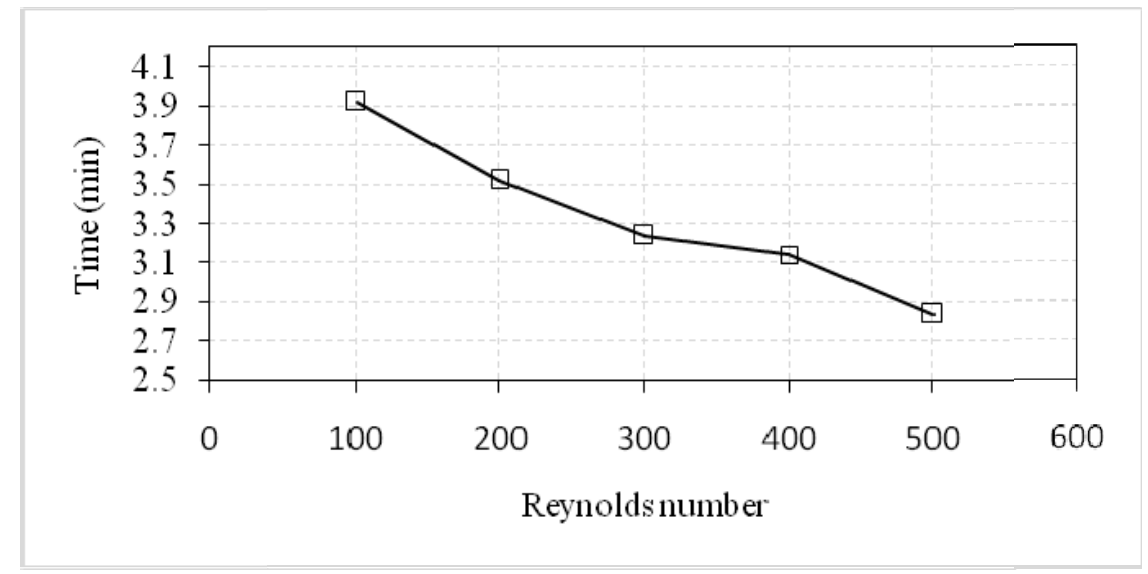

Figure 8: Effect of Reynolds Number on Thermocline Stability.

The effect of $\operatorname{Re}_{i}$ on time taken by entering fluid to create the disturbance in thermocline is shown in fig. 8. Lower $\mathrm{Re}_{i}$ is favorable for better performance of TES in terms of disturbance, but a higher $\operatorname{Re}_{i}$ is desirable from many other points of view such as cost of the system, space etc.

The above cases clearly suggest that some internal modification in design of chilled water storage tank should be made for improving the stratification for meeting the cooling requirement of 12 minutes.

\subsection{Modification in the Internal Configuration of the Thermal Storage Tank}

To dampen the inertia of the flow entering through the diffuser under charging operation at high Reynolds number, the dampers can play a significant role. They break the fluid momentum, so fluid lose their power to propagate up and disturb the thermocline. This is investigated here under different layout of the dampers. Dampers are of two perforated typesvertical arrangement and horizontal arrangement considered, as shown in fig.9. Dampers are conveniently located to dampen the flow emerging out of diffuser. 


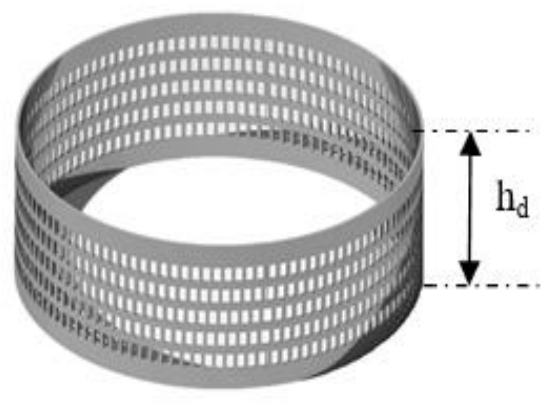

(a)

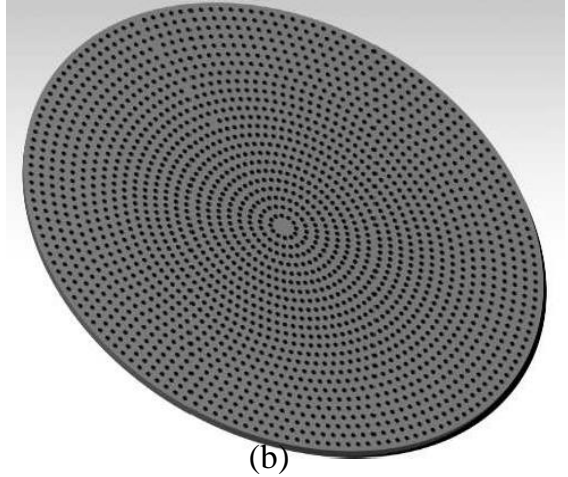

(b)

Figure 9: Perforated Dampers, (a) Vertical, (b) Horizontal.

To investigate the flow behavior emerging in presence of dampers and their impact on stratification, a computational domain same as previous case is considered. The height of damper plates $h_{d}$ is taken as 1.5 times the height of diffuser. These dampers are placed such that the flow coming out from inlet diffuser will be broken down by the dampers. Hence instead of formation of high velocity jets, a stabilized flow fills the tank.

\section{(a) Using Vertical Dampers}

Figure 10 shows temperature distribution and thermocline behavior inside the tank during charging/discharging operation in presence of vertical dampers - one, two, three and four. The thermocline is initially assumed to be at mid -height of the tank. It moves up during charging and goes down while discharging. The deformation or alteration can be observed over a period of operation- charging or discharging. It can be observed that the thermocline is moving without any debasement.

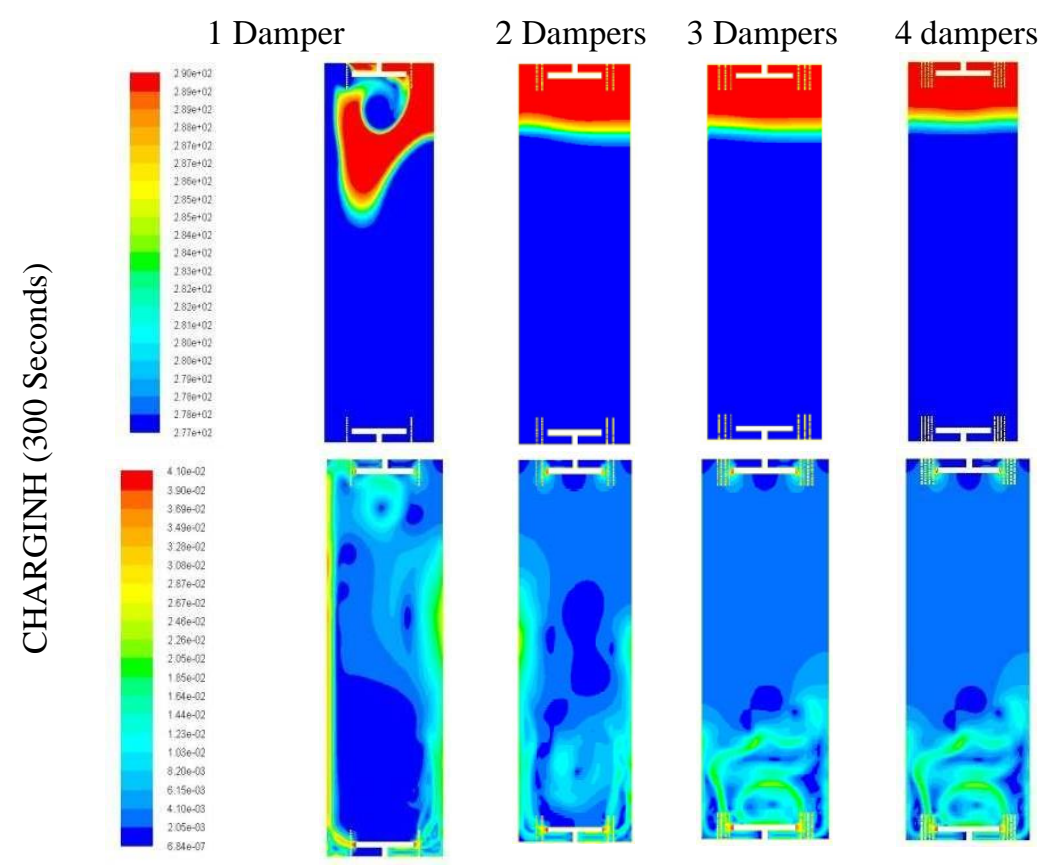



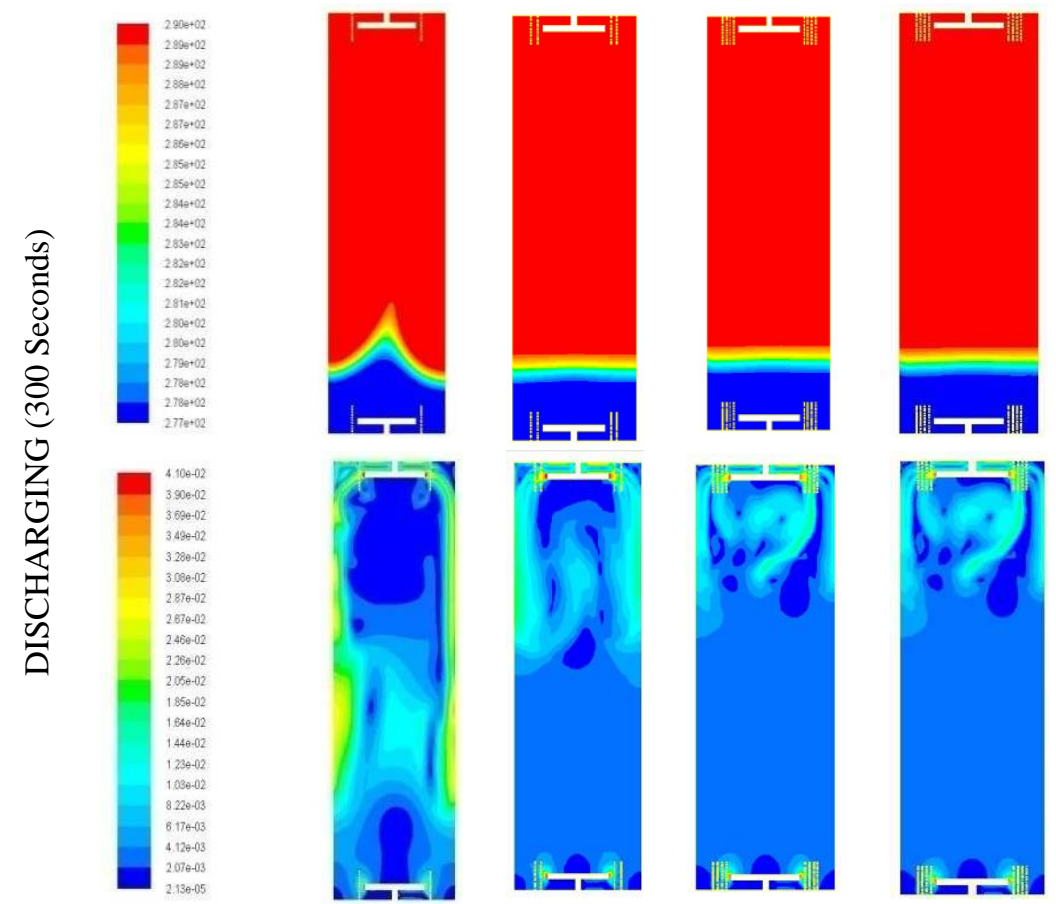

Figure 10: Temperature and Velocity Distribution.

Figure 11 shows the variation of temperature inside thermocline during charging and discharging operation of the thermal storage tank. At different time level the thermocline for a period of about 360s, it remains intact (free from disturbance) without any kind of thickening. So steady movement of thermocline at different time intervals without distortion for duration of 12 minutes during both charging and discharging cycle, indicates that the design parameters considered above results in satisfactory performance of the chilled water storage tank.

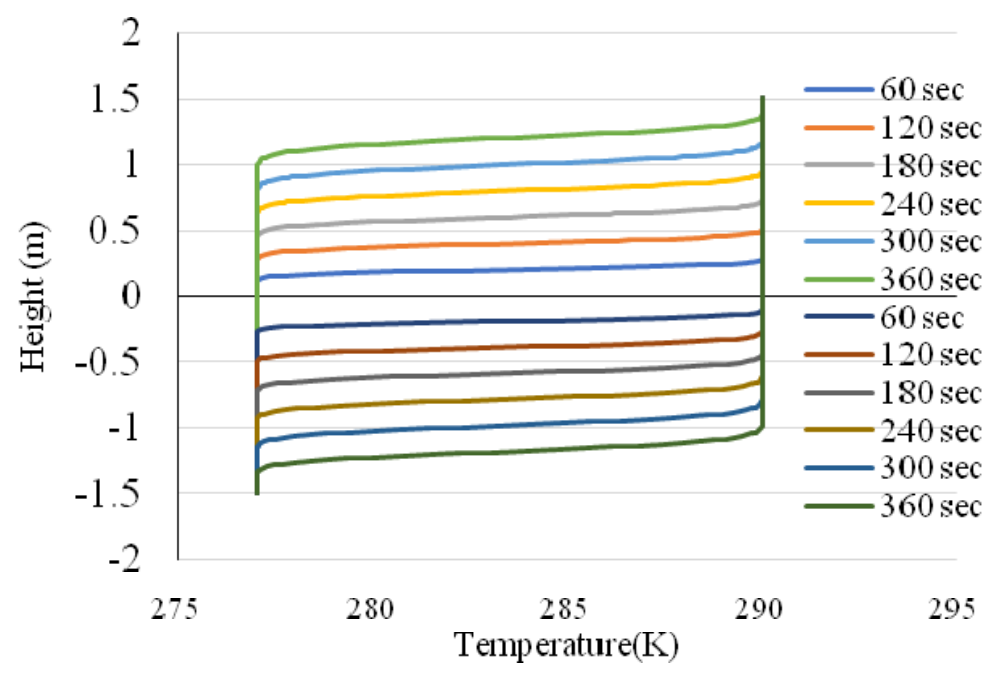

Figure 11: Temperature Variation in Thermocline at Various Time Step.

\section{(b) Using Horizontal Dampers}

To observe the effect of damper in horizontal position, investigation is performed on the same storage tank with keeping horizontal damper a distance $0.05 \mathrm{~m}$ away from diffuser and charging at $\mathrm{Re}_{\mathrm{i}}=1056$. Figure 12 shows temperature and velocity distribution after time 180s, during charging and discharging operation. Comparing result with vertical dampers it 
can be concluded that horizontal dampers are not as successful as vertical damper to preserve the thermocline.

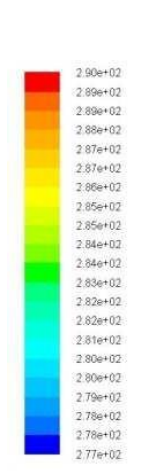

Temperature
Charging Cycle

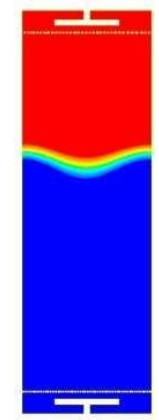

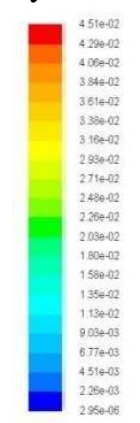

Velocity

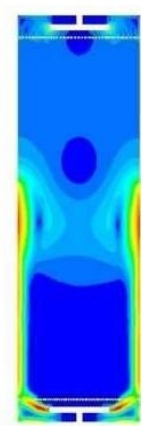

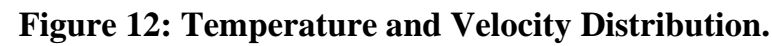

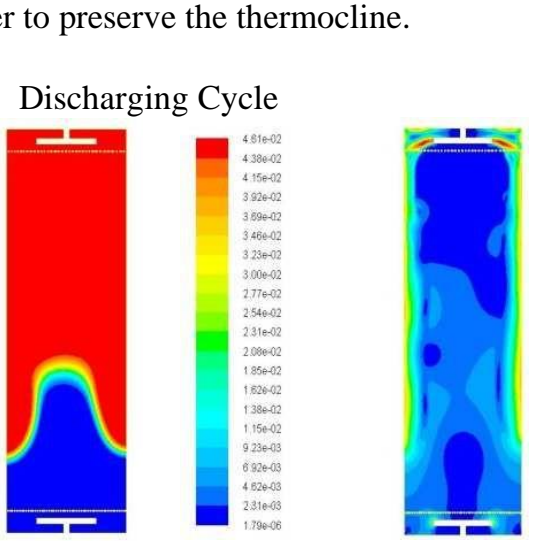

Velocity

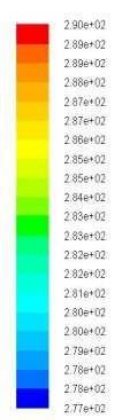

Temperature

Storage tank is expected to perform differently under few parametric changes. So, assessment of few parameters is performed here.

- $\quad$ Effect of charging and discharging rate $(\mathrm{Re})$,

- $\quad$ Effect of spacing $\left(\mathrm{S}_{\mathrm{d}}\right)$ between damper and diffuser,

- $\quad$ Effect of spacing between damper plates $\left(\mathrm{S}_{\mathrm{p}}\right)$,

- $\quad$ Effect of tank aspect ratio (H/D) on the thermocline

\section{a) Effect of Charging/Discharging Rate (Re) on the Thermocline}

To study the effect of charging/discharging rate of storage tank on the movement of thermocline, the Re is varied from792 to 6072. Increasing $\mathrm{Re}$ is expected to destabilize the thermocline due to their higher momentum. The investigation is performed with 4vertical dampers in series. The temperature contours as shown in fig. 13for charging and discharging cycle, imply that the stratification is maintained without any debasement of the thermocline till Reynolds number5808. Only thickness of the thermocline is observed to be thickened. This shows credibility of the design for a wide range of Reynolds number application.

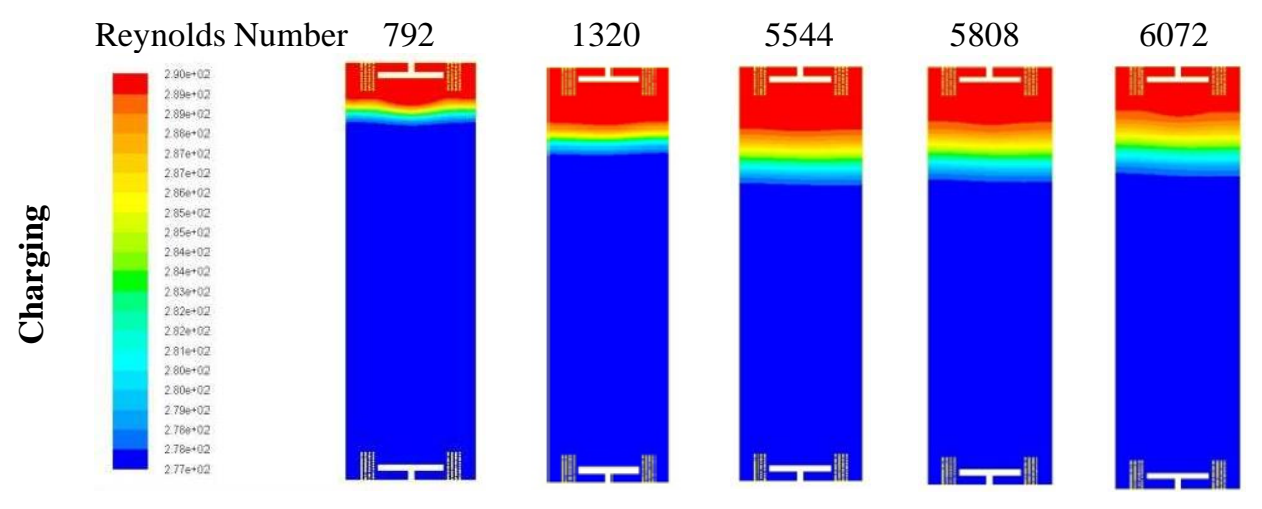



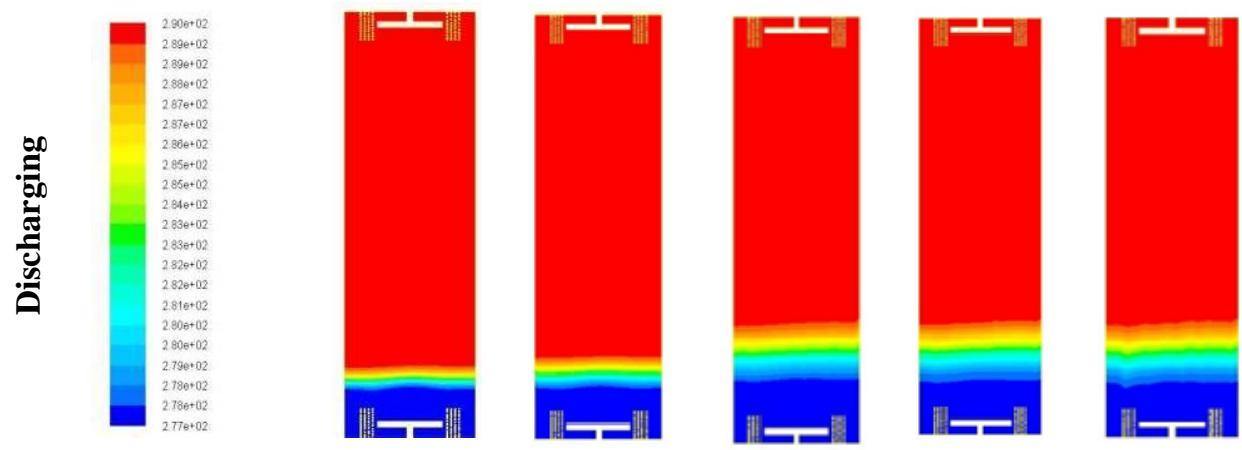

Figure 13: Effect of Re on Thermocline.

\section{b) Effect of Spacing $\left(S_{d}\right)$ Between Damper and Diffuser}

Figure 14 shows the effect of changing space between diffuser and first damper on the thermocline formed between warm and chilled water at constant rate of charging. No significant effect on thermocline for different value of $S_{d}$ equal to $1 \mathrm{~cm}$, $2 \mathrm{~cm}, 3 \mathrm{~cm}$ and $4 \mathrm{~cm}$, is observed. So, it can be concluded that spacing in-between diffuser and damper is not important.

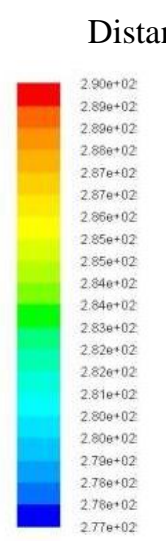

$0.01 \mathrm{~m}$

$0.02 \mathrm{~m}$

$0.03 \mathrm{~m}$

$0.04 \mathrm{~m}$

Figure 14: Effect of Space between Diffuser and Damper on Thermocline.

\section{c) Effect of Spacing $\left(S_{p}\right)$ Between Damper Plates}

Dampers (perforated walls) helps to breakdown the momentum of flow emerging from periphery of radial diffuser and passing through the damper. A better streamlined of the flow can be expected for a greater number of dampers.Figure 15 shows the effect of spacing between 4 vertical dampers with spacing $\left(\mathbf{S}_{\mathbf{p}}\right)$ in-between as $-1 \mathrm{~cm}, 2 \mathrm{~cm}$ and $3 \mathrm{~cm}$. No significant change in thermocline is observed. So, a designer may select any value as per the other parameters.

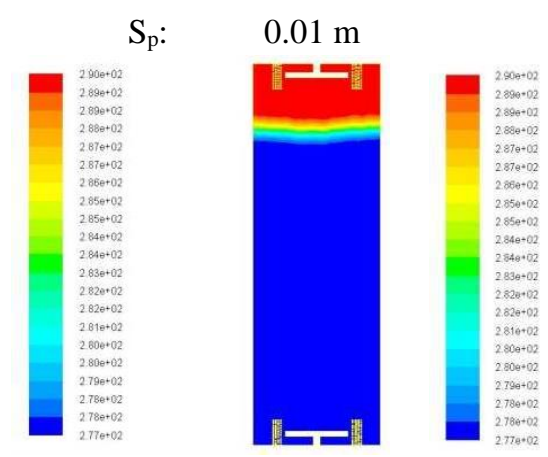

$0.02 \mathrm{~m}$
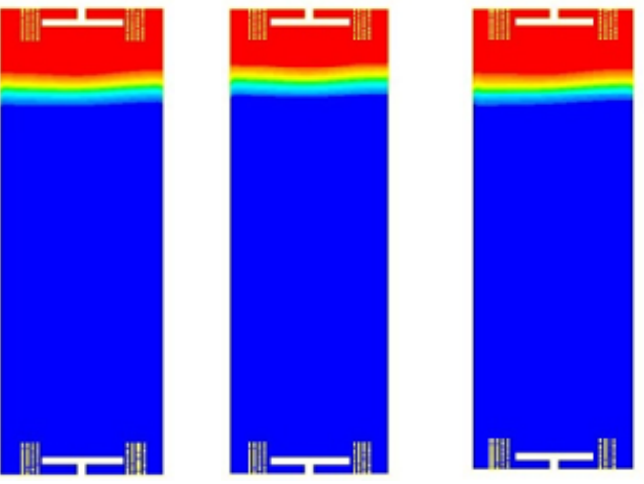


\section{d) Effect of Tank Aspect Ratio (H/D) on the Thermocline}

Varying the aspect ratio (H/D) of the storage tank by keeping height $(\mathrm{H})$ constant helps to store more stratified water and ensure to serve a designated load for the longer period. The case simulated by maintaining same D/d ratio. Figure 16 shows the effect of all these changes on the stability of thermocline with 4 dampers during charging operation at 1056 Reynolds number. Different location of thermocline can be observed which is due to changed size of the storage tank. Thermocline appears to be almost unaffected by the said parameter. So, it can be recommended that a designer change the capacity of the storage tank provided it maintains all other parameters.

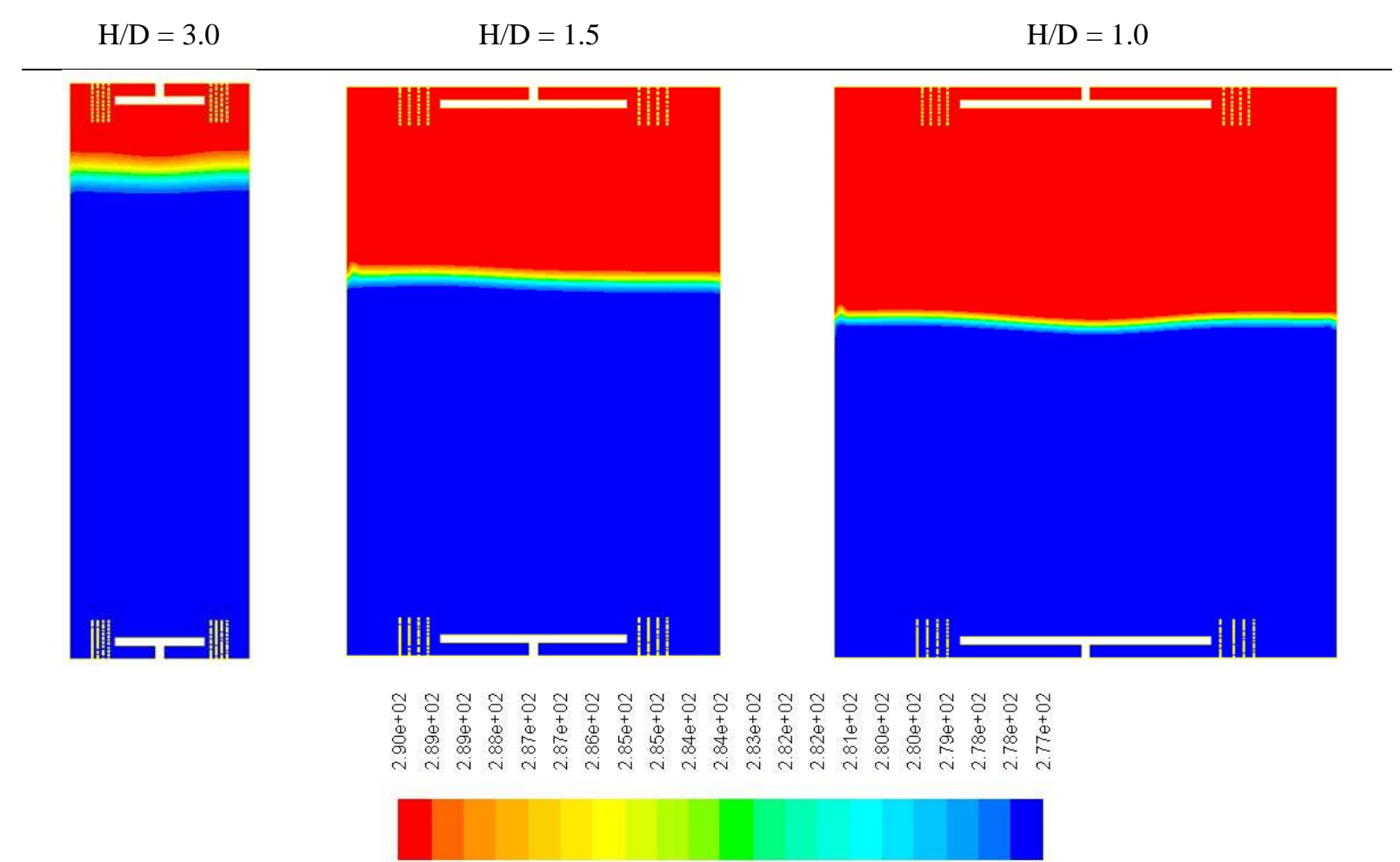

Figure 16: Effect of Changing Aspect ratio (H/D) of the Storage Tank on Thermocline.

\section{CONCLUSIONS}

Present work investigates the characteristics of thermocline during charging and discharging operation of a chilled water thermal storage tank which designed to take care of $20 \%$ of designed load of 200TR for a period of 12 minutes. Study includes theoretical calculation for the sizing of the tank along with numerical parametric study of key design parameters. Further certain modification in existing design is proposed to ensure better performance of the storage tank. Main outcome of the investigation is mentioned below:

- As diameter of diffuser increases thermocline tends to be more stable at a given charging rate.

- $\quad$ Diffuser height from tank's horizontal surface should be not be very small.

- Lower $\mathrm{Re}_{i}$ is favorable for better performance of TES in terms of disturbance, but a higher $\operatorname{Re}_{i}$ is desirable from many other points of view such as cost of the system, space etc.

- A significant improvement in thermocline stability is observed if dampers are used. Vertical dampers are more 
effective compared to the horizontal diffusers.

- Lower charging / discharging rate $(\mathrm{Re})$ is more favorable for thermocline stability if vertical dampers are used.

\section{REFERENCES}

1. W. Tipasri, T. Wongwuttanasatian. (2019). Effect of height to diameter ratio of chilled water storage tank on temperature gradient during discharging. EnergyProcedia, 156,254-258

2. J.E.B. Nelson, A.R. Balakrishnan, S. Srinivasa Murthy (1999). Experiments on stratified chilled-water tanks, International Journal of Refrigeration, 22,216-234

3. Firas M. Hasan, MaatheAbdulwahedTheeb (2018). Experimental and numerical study of neat transfer process of chilled water storage tank. Universal Journal of Mechanical Engineering,6,63-75

4. M.A.Karim. (2011). Experimental investigation of a stratified chilled-water thermal storage system. Applied Thermal Engineering,31,1853-1860

5. A. Musser \& W. P. Bahnfleth. (2001). Parametric Study of Charging Inlet Diffuser Performance in StratifiedWater Storage Tanks with Radial Diffusers: Part 2-Dimensional Analysis, Parametric Simulations and Simplified ModelDevelopment, HVAC\&R Research, 7:2, 205-222

6. C. E. Dorgan and J. S. Elleson. (1993). Design guide for cool thermal storage: ASHRAE Atlanta.

7. W.P. Bahnfleth, A. Musser. (1998). Thermalperformance of a full-scale stratified chilled-water thermalstorage tank.ASHRAE transaction, 104,377-388

8. M. Lin, S. Shao, X. Zhang, J.Vangilder, V. Avelar, X. Hu. (2015). Strategies for data center temperature control during a cooling system outage. Energy and Buildings,83,484-493 